引用格式: 陈志钢, 刘丹, 刘军胜. 基于主客交往视角的旅游环境感知与评价研究——以西安市为例 $[J]$. 资源科学, 2017, 39 (10) : 1930-1941. [Chen Z G, Liu D, Liu J S. Tourism environment perception and evaluation based on host-tourist interactions in Xi' an City[J]. Resources Science, 2017,39(10): 1930-1941.] DOI: 10.18402/resci.2017.10.12

\title{
基于主客交往视角的旅游环境感知与评价研究 以西安市为例
}

\author{
陈志钢,刘 丹,刘军胜 \\ ( 陕西师范大学地理科学与旅游学院, 西安 710119)
}

\begin{abstract}
摘 要: 东道主和游客是旅游环境中的两个关键群体,他们之间的互动将对旅游环境的感知与评价产生重要 影响。本文以陕西西安为例, 运用实地问卷调查和结构方程模型, 研究东道主、游客对城市旅游环境的感知和评 价, 进而探讨旅游环境、居民与游客三者之间的互动关系。结果表明: 旅游环境感知质量正向影响居民好客度、友 好意愿与游客满意度; 居民好客度与游客满意度之间呈正相关关系; 游客行为影响旅游环境, 但对居民好客度不具 有显著影响。深入分析发现旅游环境、东道主的态度和游客的意向与行为之间构成了相互影响的逻辑路径。最后 从主客交往视角, 为城市旅游环境感知质量与评价的提升提出了建议。
\end{abstract}

关键词: 旅游环境; 居民好客度; 游客满意度; 游客行为; 主客交往;西安市

DOI: $10.18402 /$ resci.2017.10.12

\section{1 引言}

旅游环境一直是国际旅游学术界重要的研究 领域 ${ }^{[1]}$, 也是当前人地关系研究的重要内容。东道 主和旅游者是旅游开发和规划中的两个关键群体 ${ }^{[2]}$ 。 旅游业的发展不仅需要考虑开发商的效益与旅游 者的体验, 同时也需要兼顾旅游景区当地居民的利 益和态度。旅游地的主客交往关系是旅游理论研 究中最富有创造力的三个命题之一 ${ }^{[3]}$, 是对社会交 往研究的进一步细化研究, 但与一般的交往理论相 比,又具有地理空间、交往结构、交往群体等方面的 特殊性 ${ }^{[4]}$ 。因而, 无论从理论上还是实践上, 研究旅 游环境和主客交往都对推动城市旅游的可持续发 展与和谐人地关系的构建有重要意义。

近年来自驾游、自助游与背包游的兴起, 以及 旅游者对参与性、体验性、融人性需求的增强, 主客 交往也日渐频繁。同时由于互联网科技和电子商
务的繁荣和普遍化,游客在规划旅游行程时有了更 多样化的信息选择,旅游目的地在进行宣传营销时 就面临着如何取得潜在旅游者关注和信任的挑 战。而东道主作为旅游目的地的重要旅游资源和 “真实”与 “无私”信息的传播者 ${ }^{[5]}$, 是旅游者在旅游 地必定会交往的群体 (过客式或浪漫式) ${ }^{[6]}$, 更是旅 游者获取信息和体验目的地 “原真性”的重要途 径。已有研究发现东道主待客行为将对游客的消 费决策及旅游体验满意度产生重要影响, 而旅游者 对东道主的印象直接影响了他们对整个城市形象 的感知 ${ }^{[7,8]}$ 。那么主客交往过程中, 游客与东道主对 彼此的评价是什么? 进而又是如何影响其对旅游 环境的评价的?

基于此,文章通过对西安游客与居民进行问卷 调查, 从主客交往的角度, 引人满意度、好客度、游 客行为及意向等,通过构建结构方程模型, 探讨游

收稿日期: 2016-11-06; 修订日期: 2017-06-10

基金项目: 国家自然科学基金项目(41671134); 陕西师范大学中央高校基本科研业务费项目(GK201002039); 陕西师范大学人文社会科 学研究基金项目(10SYB05)。

作者简介: 陈志钢, 男, 湖南石门人, 博士, 副教授, 主要从事旅游管理与旅游规划、旅游移民与旅游商业化研究工作。

E-mail : zsuczg@163.com 
境, 更是游客在整个旅游过程中所有感知到的环境

客、居民与旅游环境三者的互动关系, 以期为旅游 环境监测与旅游环境治理提供理论支撑。

\section{2 基本概念及研究假设}

\section{1 旅游环境与好客度}

早在 1981 年,陈光裕就提出旅游环境是能让人 们在进行旅游活动时产生美感, 并获得精神与物质 享受及知识乐趣的环境,包括自然、社会、经济、政 治、科学技术条件等环境 ${ }^{[9]}$ 。

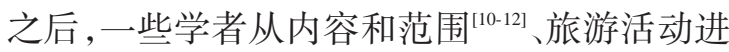
行的条件 ${ }^{[13]}$ 对旅游环境进行了分类和补充, 也有学 者从旅游者角度 ${ }^{[14,15]}$ 、旅游目的地角度 ${ }^{[16]}$ 对旅游环 境进行内涵的阐释。在国内, 学者们已陆续对吐鲁 番、承德、三亚、南京、苏州、洛阳、开封、青岛等城 市, 及鼓山、青海湖、黄山、沾沽湖、龙虎山等景区的 旅游环境进行过调查分析。大都通过评估旅游地 旅游环境质量及其承载力分析该地旅游环境的现 状和问题, 从而提出对策 ${ }^{[17-19]}$ 。其中旅游环境质量 主要从游客的角度对旅游景观、自然生态、环境氛 围、旅游信息、服务、设施、社会、经济等方面进行评 价。从居民的角度研究较多的是目的地居民对旅 游环境影响的感知和态度 ${ }^{[20,21]}$ 。在国外, 学者们对 世界旅游业发展的不同阶段有不同的旅游环境研 究侧重点 ${ }^{[22]}$, 包括观光游阶段的旅游环境承载力 ${ }^{[23]}$, 度假游阶段的旅游竞争力 ${ }^{[24]} 、$ 生态旅游 ${ }^{[25]} 、$ 区域旅游 ${ }^{[26]} 、$ 旅游可持续发展 ${ }^{[27,28]}$ 等, 以及休闲游阶段的旅游环 境感知 ${ }^{[29]} 、$ 旅游创新 ${ }^{[30]}$ 、旅游环境税 ${ }^{[11]}$ 等。

对于西安市的旅游环境, 杜忠潮等构建了旅游 景观、环境适宜性、基础设施、社会服务等四个指标 进行评价, 并将其与宝鸡、咸阳进行了对比 ${ }^{[32}$; 郭雅 宁通过分析西安旅游环境的现状认为西安的旅游 环境处于基本健康的发展状态,但发展前景不容乐 观,需要对软硬质环境进行建设规划,优化西安的 旅游环境 ${ }^{[33]}$; 张悦调查了外国游客对西安旅游的六 方面 (旅游吸引物、旅游服务与设施、旅游交通、旅 游环境、旅游信息和旅游安全) 的评价,总的来说旅 西外国游客对西安的旅游是满意的 ${ }^{[34]}$ 。

综上,学者们普遍认为旅游环境包括自然环境 与人文环境。为深人剖析旅游环境与好客度之间 的互动关系, 本文对旅游环境的内涵做了进一步的 补充, 认为旅游环境不仅是居民赖以生存的生活环
系统, 其包括旅游吸引物、自然生态、社会服务、环 境氛围、旅游信息、基础设施等。

根据多地旅游业的发展经验, 东道主的“好客 精神” 是旅游地吸引旅游者到访的重要因素之一, 也是目的地旅游软实力的表征,引起了众多学者的 关注 ${ }^{[35]}$ 。如李天元等对“好客”进行了定义,并对 “好 客”的具体表现方式进行了梳理, 同时认为旅游地 发展阶段和游客行为对居民“好客”有重要影响 ${ }^{[36]}$; 李正欢探讨了“好客”的历史发展演变及旅游商业 化中的好客模式 ${ }^{[37]}$;李春霞从旅游人类学的“主-客” 范式中分析了中国传统语境下的好客精神 ${ }^{[381}$; 还有学 者研究了旅游原真性得以持续下 “好客” 的边界 ${ }^{[39]}$ 和 好客旅游的开发 ${ }^{[40]}$ 与发展 ${ }^{[4]}$ 。由于 “好客山东”旅游 形象品牌的典型性, 很多学者从其品牌评价 ${ }^{[42,43]}$ 、营 销模式 ${ }^{[4]} 、$ 品牌建设 ${ }^{[4]}$ 与开发 ${ }^{[46]}$ 、游客感知的好客 度 ${ }^{[40]}$ 等进行过相关研究。这些研究主要进行的是 定性分析, 量化研究十分有限, 如马红丽以六大中 国热点旅游城市为案例, 探讨了外国游客在不同的 时间断面上对这 6 个城市居民好客度的评价 ${ }^{[4]}$ 。

好客的客体不仅是身边熟悉的人,还应包括来 访的陌生人, 特别是游客 ${ }^{[35]}$ 。目前大多数研究认为 居民好客为城市旅游社会服务环境的一部分, 事实 上旅游环境的其他方面对居民的好客度也有不同 程度的影响。按照多克西的“愤怒指数”理论 ${ }^{[48]}$ 和巴 特勒的“旅游地生命周期”理论 ${ }^{[49]}$, 游客的持续介人 会对居民的生活环境产生影响,进而居民对游客的 态度也会有所变化,因此城市旅游环境质量是影响 居民好客度的重要因素。

综上,一般来说, 凡经历一个地方, 人们在与该 地的不断互动之中便会形塑关于地方的观念与态 度, 这本身就包含了对好客度认知的多重向度。根 据学者们对 “好客”及 “好客精神” 的概念解释, 将本 文研究的好客度定义为作为个体的旅游目的地居 民或作为群体的该地社会, 对旅游者的热情友好程 度, 主要表现在待客态度和待客行为之上。

本研究将居民好客度作为中介变量进行研究， 将其独立在旅游环境系统之外。

基于上述,提出以下假设:

H1a: 游客对旅游环境感知和评价越好, 越认为 
居民的好客度高

$\mathrm{H} 1 \mathrm{~b}$ : 居民对旅游环境感知和评价越好, 对游客 的好客度越高

\section{2 游客视角: 旅游环境、好客度、游客满意度及行 为意愿}

游客满意度是调查旅游现状的一个重要指标, 是指游客通过旅游活动过程的感知和事先预期的 对比,两者之间产生的心理差距。已有较多研究用 游客满意度理论对旅游地的旅游环境进行测评。 一般而言, 游客感知的旅游环境越好, 满意度越高 ${ }^{[50-52]}$ 。 当然游客对旅游环境的满意程度会产生一系列连 锁反应, 如影响游客对旅游目的地的选择、旅游产 品和服务的消费、是否重游、是否推荐给亲友等方 面 ${ }^{[53]}$ 。

随着主客交往强度的深人和频率的增强, 好客 精神越来越成为旅游地重要的无形旅游吸引物, 对 游客逗留城市期间的旅游体验质量有相当重要的 影响 ${ }^{[35]}$, 从而成为影响游客满意度的重要因素。此 外好客精神是旅游目的地建立形象的重要手段,因 其可感知性、可评价性和传播性较强, 进而很容易 影响游客的推荐度和重游意愿。

基于上述, 提出以下假设:

$\mathrm{H} 2$ : 游客对旅游环境感知越好, 游客满意度 越高

$\mathrm{H} 3$ : 游客对旅游环境感知越好, 推荐意愿越强

$\mathrm{H} 4$ : 游客对旅游环境感知越好, 重游意愿越强

H5 : 居民好客程度越高, 游客满意度越高

H6: 居民好客程度越高, 游客推荐意愿越强

H7 : 居民好客程度越高, 游客重游意愿越强

$\mathrm{H} 8$ : 游客满意度越高, 推荐意愿越强

H9: 游客满意度越高, 重游意愿越强

研究模型如图 1所示。

\section{3 居民视角: 旅游环境、游客行为、好客度和友好 意愿}

本文中的游客行为仅指居民能感知到的游客 在旅游中表现出来的行为, 不包括游前和游后行 为; 友好意愿是指居民对潜在游客的态度和行为倾 向。游客行为与旅游环境之间的关系主要体现在 旅游影响方面,很多地方的旅游业发展经验表明, 游客的负面行为会不同程度地破坏城市环境, 而游

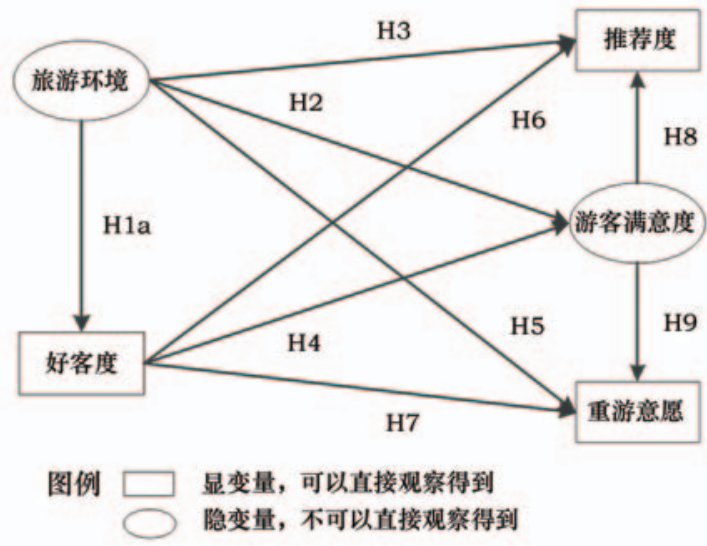

图 1 基于游客视角的关系模型

Figure 1 The relation model based on the tourist's perspective

客的示范行为和积极经济行为能加快旅游环境的 建设和巩固 ${ }^{[54]}$ 。城市在发展旅游业的过程中, 利益 相关群体 (政府、企业)会对整个旅游环境进行调整 和改善, 以获取相关利益。因此城市的旅游环境, 特别是硬件环境, 会获得很大的提升, 居民的生活 环境便越来越好。当居民的利益得到保障后,自然 对游客热情友好,也欢迎更多游客的到来。因此旅 游环境成了影响居民友好意愿的重要因素。

游客行为对居民好客度和友好意愿影响的研 究鲜少,但很多研究表明游客行为对居民的社会生 活和经济文化都产生了重要作用 ${ }^{[4,36]}$,主要表现在居 民的价值观、个人行为、家庭结构、生活方式、道德 观念、宗教、语言、健康等方面 ${ }^{[5]}$ 。事实上, 游客行为 不仅对居民自身有影响,还会改变居民对游客的态 度一一在主客交往的不同阶段呈现出从融洽、冷 漠、恼怒到公开对抗的变化趋势 ${ }^{[48]}$ 。因此游客行为 会影响居民的好客度,进而影响其友好意愿。

基于上述,提出以下假设：

$\mathrm{H} 10$ : 游客行为越正面, 居民对旅游环境的感知 越好

$\mathrm{H} 11$ : 游客行为越正面, 居民好客度越高

$\mathrm{H} 12$ : 游客行为越正面, 居民友好意愿越强

$\mathrm{H} 13$ : 居民对旅游环境的感知越好, 友好意愿 越强

H14: 居民好客度越高, 友好意愿越强。

研究模型如图 2 所示。 


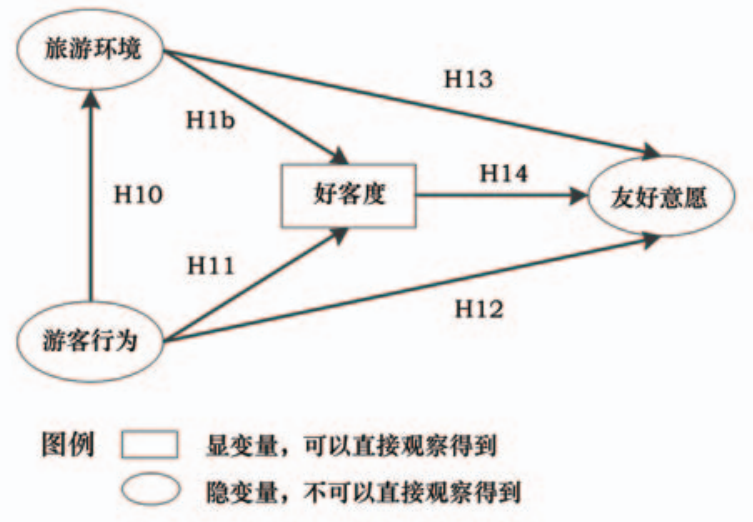

图 2 基于居民视角的关系模型

Figure 2 The relation model based on the host's perspective

\section{3 研究方法}

\section{1 西安市旅游环境质量评价指标}

为了保证全面准确地测量西安市旅游环境中 目前存在的问题,本报告的测量指标将从两个方面 获取。首先从新浪微博上获取 3 个月 (2016.4.12016.6.30) 网友对西安市旅游环境的 595 条有效的 负面评论 (剔除与西安市旅游环境无关的内容, 例 如心情不好等, 以及广告宣传相关评论), 因为负面 评论能够更准确地得知西安市旅游环境目前存在 的问题。通过文本分析,即对文本的表示及其特征 量的选取,利用 Rost Content Mining6.0 软件对所有 的微博评论进行词频分析, 从而确定西安市旅游环 境质量评价指标(结果如表 1 所示)。其次参考上述 与旅游环境质量研究相关的文献,进一步完善测量 指标。

\section{2 问卷设计及其他变量测量}

游客问卷的设计分为四大部分：

(1)旅游环境质量感知评价。基于上述方法, 最终共确定了 36 个因子作为观测变量。其中 6 个 题项测量旅游吸引物, 6 个题项测量自然生态, 6 个 题项测量基础设施, 7 个题项测量社会服务, 4 个题 项测量环境氛围, 7 个题项测量旅游信息。

(2) 游客视角的居民好客度测量, 测量指标参 考马明关于 “好客山东”的研究 ${ }^{[3]}$, 共计 11 个题项。

(3) 游客满意度、推荐度和重游意愿的测量。 其中满意度用 4 个题项测量。

（4）个人基本信息。包括年龄、性别、来源地、 职业、教育背景、月收人、旅行方式、旅游次数、停留
时间、获取信息的途径、旅游动机等。

居民问卷也分为四大部分：

(1) 旅游环境质量感知评价, 题项和游客卷 相同。

（2）居民视角的居民好客度及友好意愿测量， 前者题项和游客卷相同, 后者用 “欢迎游客的到 来?”“愿意接待或帮助游客?”两个变量来测量。

(3) 游客行为评价, 参考孟威等关于旅游主客 交往理论的研究 ${ }^{[5]}$, 共选取 13 个观测变量, 其中 5 个 题项测量主客交往行为, 3 个题项测量经济行为, 3 个题项测量负面行为, 2 个题项测量示范行为。

（4）个人基本信息。包括性别、年龄、在西安的 居住时间、民族、与旅游业的关系、教育背景、月收 人等。除了个人基本信息, 其他题项均用李克特 5 分量表进行测量。

\section{3 样本说明}

此次调查主要分为两个阶段进行:

(1) 预调研阶段 (2016.7.1-2016.7.5): 通过网上 在线进行, 调查对象为在西安旅游过的游客和西安 本地居民,各 100 名, 根据调研结果对问卷问项进行 再设计。

(2) 实地调研阶段(2016.7.9-2016.7.16)。采用 偶遇抽样调查法, 调查对象为已在西安游过的游客 以及在西安景点周边居住的和旅游从业人员, 问卷 调研地点为机场、高铁站、兵马俑、陕西历史博物 馆、大明宫、大雁塔、小寨等游客与居民集中的地 方。发放居民问卷 1000 份, 游客问卷 1000 份, 外国 游客问卷 100 份,再加上被调查者在线填写的问卷, 剔除无效样本后,最终回收居民有效问卷 935 份, 问 卷有效率为 $85.0 \%$, 游客有效问卷 983 份, 问卷有效 率为 $98.3 \%$ 。

在被调查的游客样本中, 男女比例分别为 $50.4 \%$ 和 $49.6 \%$; 年龄大都在 25 岁以下 $(68.2 \%)$; 受 教育程度较高, 本科及以上占 $71.5 \%$; 收人方面, 3000 元以下群体最多 (64.4\%), 其次是 3000 4999 元 $(16.8 \%), 5000 ~ 7999$ 元群体为 $12.3 \%$; 因调查时 间为暑假,正是西安修学游的高峰期,所以被调查 者中学生群体居多 $(58.4 \%)$, 其次是教师群体 $(8.1 \%)$; 他们来自全国各地,东到上海,西到乌鲁木 齐, 北到哈尔滨,南到海南; 大部分游客是第一次来 


\section{表 1 微博网络文本词频分析}

Table 1 Frequency analysis of microblogging network text words

\begin{tabular}{|c|c|c|}
\hline 主要概念 & 概念提取(频数) & 文本内容分析(频数) \\
\hline \multirow[t]{8}{*}{ 社会服务 } & 旅游价格 (56) & 门票价格高(32); 收费不合理(5); 物价高(15); 停车费贵(1); 导游费贵(1); 景区实行通票(2) \\
\hline & 治安状况 (16) & 提高治安 (6); 小偷多 (3); 推销现象 (4); 残疾人士 (2); 黄牛(1) \\
\hline & 市民热情友好(8) & 西安市民素质(4);市民不热情(4) \\
\hline & 导游素质(6) & 导游服务不热情 (2); 导游少推销购物 (4) \\
\hline & 旅游容量(46) & 人太多(37); 景区拥挤(6); 限制人流(3) \\
\hline & 服务质量(37) & 服务一般 (15); 出租车司机 (3); 改善交流素质 (5); 住宿服务态度需改进 (1); 游客耐心些 $(1)$; 执 \\
\hline & & 法人员素质低(1);景区应设置饮水地方 (2)增加服务窗口(8);增加自助取票点 (2) \\
\hline & 旅游产业政策( 12) & 整体旅游监管(12); 防拥堵措施(1) \\
\hline \multirow[t]{6}{*}{ 自然生态 } & 绿化覆盖率 $(27)$ & 加强绿化(27) \\
\hline & 公共环境卫生 (87) & 街道卫生差 (46); 垃圾多 (9); 推位杂乱 (1); 居住环境优化 (1); 则所卫生差 (6); 环境治理(24) \\
\hline & 空气质量(13) & 空气质量(9);治理雾䨪(2); 风沙大(2) \\
\hline & 气候(19) & 太热(14); 气候干燥 (5) \\
\hline & 水质(4) & 改善水资源 (1);水污染(1);河流治理(2) \\
\hline & 污染治理(2) & 污染严重(2) \\
\hline \multirow[t]{2}{*}{ 环境氛围 } & 整体风貌 (1) & 市貌偏旧 (1) \\
\hline & 历史文化气息(13) & 增加文化氛围(6);商业气息浓厚(2); 文物保护(5) \\
\hline \multirow[t]{5}{*}{ 旅游信息 } & 互联网服务 (13) & 网络化水平较低 (1); 免费WIFI(7); 支付宝普及 (1); 网上预约 (3); 景区科技的使用 (1) \\
\hline & 标识、导览信息(30) & $\begin{array}{l}\text { 标识不明显 }(23) \text {; 公交站牌不明确 (2); 地铁出人口醒目一些 }(2) \text {; 机场火车站需要更多地景区介 } \\
\text { 绍与引导 }(2) \text {; 餐厅附近信息完善 }(1)\end{array}$ \\
\hline & 信息咨询服务( 8) & 咨询服务建设 (4); 提前预定(2);西安官方网站(2) \\
\hline & 免费旅游宣传资料充足 (1) & 免费发放景区介绍资料(1) \\
\hline & 旅游促销力度 (7) & 加大旅游宣传推广(5);宣传与真实不符(1);网络宣传力度不够(1) \\
\hline \multirow[t]{5}{*}{ 基础设施 } & 内外交通发达(115) & $\begin{array}{l}\text { 交通不便 (94); 公交车增加 (5); 地铁线路少(4); 多开通旅游专线(2); 出租车拒载(2); 改善交通 } \\
\text { 基础设施 (5); 公交车空调 (3) }\end{array}$ \\
\hline & 食宿条件(5) & 住宿有待提高 (1);食品方面多一些监督 (1); 旅游景点商品质量(1);清真餐厅少(2) \\
\hline & 娱乐设施完善(1) & 完善娱乐设施安全(1) \\
\hline & 购物设施 (3) & 高品质旅游纪念品(1);不要有假货(2) \\
\hline & 公共休息设施完善(38) & 休息设施 (8);完善基础设施(25);垃圾桶 (5) \\
\hline \multirow[t]{2}{*}{ 旅游吸引物 } & 景区景点丰富多样(2) & 景点更加多元(2) \\
\hline & 旅游节事活动(3) & 组织一些活动 (1); 多一些表演 (1); 表演有些夸张 (1) \\
\hline
\end{tabular}

西安旅游 $(53.5 \%)$, 停留时间基本上在两天及以上 $(95.7 \%)$, 来西安的旅游目的主要有休闲度假 $(57.3 \%)$ 、观光 $(55.0 \%)$ 和文化交流 $(20.2 \%)$ 。

在被调查的居民样本中, 男女比例占 $43.3 \%$ 和 $56.7 \%$; 年龄集中在 20 30 岁 $(67.3 \%)$; 受教育程度 主要集中在大学本科 $(64.3 \%)$ 和高中 $(20.0 \%)$; 收人 基本上在 5000 元以下 $(77.7 \%)$; 被调查者主要是汉 族人 $(94.8 \%)$, 大部分不从事旅游业 $(82.6 \%), 10.4 \%$ 家中有人从事旅游业, $7.1 \%$ 本人从事旅游业。

\section{4 结果及分析}

\section{1 旅游环境感知质量现状分析}

旅游环境感知质量现状反映了游客与本地居
民对西安旅游环境的总体评价, 是进一步基于主客 交往视角构建旅游环境感知与评价的基础。

无论从游客的角度还是居民的角度,气候、空 气质量、污染治理、旅游容量、水质与公共卫生的感 知质量较低; 历史文化氛围、景观特色、观赏价值感 知质量较高。景区信息咨询、景点多样性、互联网 服务、公共休息和导游服务的感知质量居中, 仍需 提高。由于居民长时间居住在旅游目的地, 对自然 生态环境的了解比游客深人, 而本次调查的时间为 夏季, 空气质量还算良好, 事实上西安冬天的雾䨪 是比较严重的, 所以在空气质量的评价上游客比居 民要高很多(如图3 所示)。 


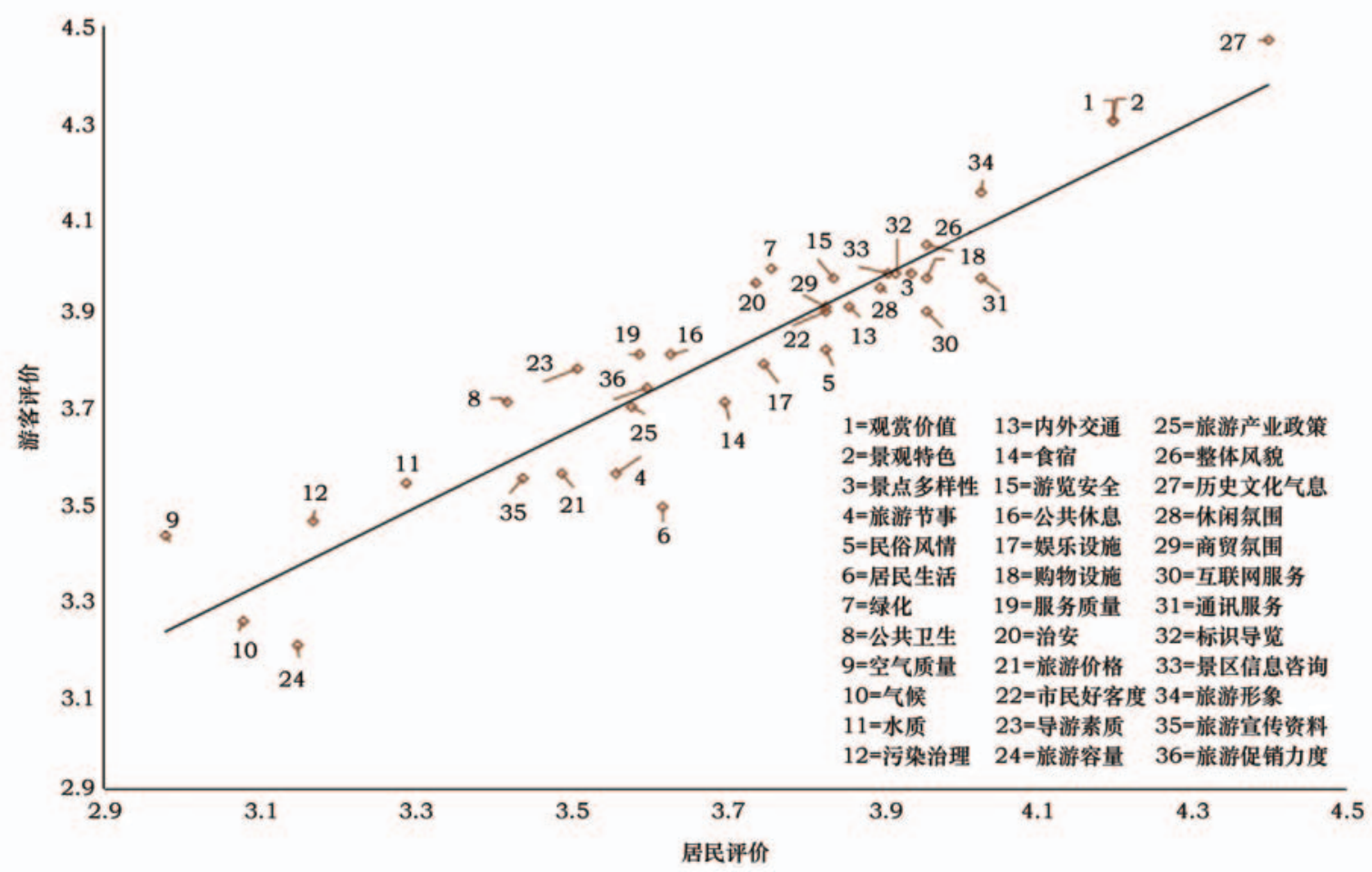

图 3 游客-居民对西安市旅游环境质量各指标的评价

Figure 3 The evaluation of tourist-host on the quality of tourism environment indicators in Xi' an

总的来说, 人们对西安市旅游环境的评价不算 太高, 普遍认为景区的人流量较大(3.17), 气候变化 无常 (3.17), 空气质量不如人意(3.21)。此外对于 西安市污染治理 (3.32) 和旅游免费宣传资料印发 (3.50) 的评价也较低。但对于旅游景观的观赏价值 (4.25)、特殊性 (4.26) 以及西安整个历史文化氛围 (4.44)还是相当认可的(如图 4所示)。

\section{2 信度和效度分析}

问卷调研的数据质量通过 SPSS20.0 进行检 验。信度用 Cronbach's $\alpha$ 系数作为指标, 普遍认为 Cronbach 's $\alpha$ 系数在 0.7 以上则信度良好。检验结 果如表 2 所示, 两份问卷所有变量的 $\alpha$ 系数均在 0.8 以上, 且总量表的 $\alpha$ 系数在 0.9 以上, 说明本问卷信 度良好。游客问卷的 $K M O$ 值为 0.966 , 居民问卷的

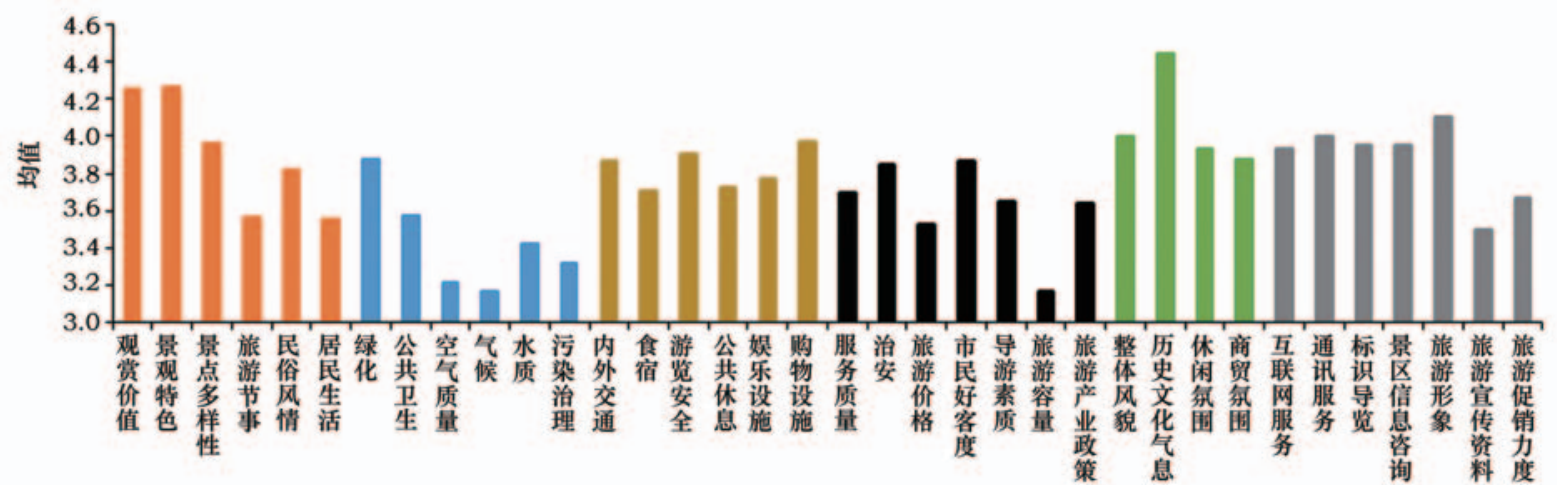

图 4 西安市旅游环境质量各指标总体评价均值

Figure 4 The mean value of the overall evaluation to the quality of tourism environment indicators in $\mathrm{Xi}$ ' an 
表 2 关系模型的Cronbach's $\boldsymbol{\alpha}$ 系数

Table 2 Cronbach's $\alpha$ value of the relation model

\begin{tabular}{llccc}
\hline \multirow{2}{*}{ 变量 } & Cronbach's $\alpha$ & $\begin{array}{c}\text { 基于标准化项的 } \\
\text { Cronbach's } \alpha\end{array}$ & 项数 \\
\hline 游客视角 & 旅游环境 & 0.948 & 0.949 & 36 \\
& 好客度 & 0.924 & 0.926 & 11 \\
& 满意度 & 0.900 & 0.900 & 4 \\
& 忠诚度 & 0.844 & 0.846 & 2 \\
& 总量表 & 0.965 & 0.966 & 53 \\
居民视角 & 旅游环境 & 0.944 & 0.945 & 36 \\
& 好客度 & 0.926 & 0.927 & 11 \\
& 游客行为 & 0.856 & 0.853 & 13 \\
& 友好意愿 & 0.869 & 0.870 & 2 \\
& 总量表 & 0.942 & 0.945 & 62 \\
\hline
\end{tabular}

$K M O$ 值为 0.939 , Bartlett 球形度检验 $P$ 值为 0.000 , 说明通过问卷收集的数据效度较高, 可对数据进行 进一步分析。

\section{3 结构模型检验}

运用AMOS17.0 最大似然法进行分析, 考察了
模型整体的拟合优度,如表 3 所示, 主要考察了绝对 适配度指标 $\left(\chi^{2} / d f 、 G F I 、 A G F I 、 R M S E A\right)$ 、增值适配度 指标 $(N F I 、 C F I 、 I F I 、 R F I)$ 和简约适配度指标 $(P N F I$ 、 $P G F I)$, 每项指数均在标准范围内, 说明本模型的拟 合度较好,通过检验,可根据此模型进行分析。

显著路径系数如表 4 所示, 根据结果假设, $\mathrm{H} 3$ 、 H4、H6、H7、H11、H12 未得到验证，其他假设均 成立。

旅游环境 $\rightarrow$ 好客度的标准化路径系数分别为 $0.706 、 0.665, C R$ 值和 $P$ 值均显著, 假设 $\mathrm{H} 1 \mathrm{a} 、 \mathrm{H} 1 \mathrm{~b}$ 成 立。无论从游客的角度还是居民的角度, 旅游环境 都与居民好客度呈正相关关系。每个城市在其旅 游发展的不同阶段,旅游环境都会因游客、政府及 其他相关利益群体的介人而呈现出不同形态, 也对 居民的生活产生不同程度的影响, 从而反过来影响 居民对游客的态度。

旅游环境 $\longrightarrow$ 游客满意度、好客度 $\rightarrow$ 游客满意度 的标准化系数分别为 $0.571 、 0.276, C R$ 值和 $P$ 值均

\section{表 3 关系模型拟合优度指数}

Table 3 The goodness-of-fit value of the relation model

\begin{tabular}{lcccccccccc}
\hline 拟合指数 & $\chi^{2} / d f$ & $G F I$ & $A G F I$ & $R M S E A$ & $N F I$ & $C F I$ & $I F I$ & $R F I$ & $P N F I$ & $P G F I$ \\
\hline 标准 & $<5$ & $>0.9$ & $>0.9$ & $<0.05$ & $>0.9$ & $>0.9$ & $>0.9$ & $>0.9$ & $>0.5$ & $>0.5$ \\
游客视角理论模型 & 3.899 & 0.962 & 0.942 & 0.044 & 0.971 & 0.978 & 0.978 & 0.961 & 0.736 & 0.741 \\
居民视角理论模型 & 3.357 & 0.966 & 0.949 & 0.043 & 0.956 & 0.969 & 0.969 & 0.942 & 0.725 & 0.735 \\
\hline
\end{tabular}

注:标准数据来源于吴明隆 $(2010)^{[56]}$ 。

表 4 关系模型的显著路径系数

Table 4 The significant path coefficient of the relation model

\begin{tabular}{|c|c|c|c|c|}
\hline 编号 & 假设基本内容 & 标准化路径系数 & $C R$ & $P($ 支持强度 $)$ \\
\hline H1a & 旅游环境 $\rightarrow$ 好客度 & 0.706 & 16.194 & ***(强力支持) \\
\hline $\mathrm{H} 2$ & 旅游环境 $\longrightarrow$ 游客满意度 & 0.571 & 12.062 & $* * *$ (强力支持) \\
\hline $\mathrm{H} 3$ & 旅游环境一推荐度 & -0.001 & -0.035 & 0.972 (不支持) \\
\hline $\mathrm{H} 4$ & 旅游环境一重游意愿 & 0.027 & 0.612 & 0.540 (不支持) \\
\hline H5 & 好客度 一游客满意度 & 0.276 & 7.952 & *** (强力支持) \\
\hline H6 & 好客度一推荐度 & 0.032 & 1.036 & 0.300 (不支持) \\
\hline $\mathrm{H} 7$ & 好客度 $\rightarrow$ 重游意愿 & -0.065 & -1.916 & 0.055 (不支持) \\
\hline $\mathrm{H} 8$ & 游客满意度 $\rightarrow$ 推荐度 & 0.806 & 18.768 & $* * *$ (强力支持) \\
\hline H9 & 游客满意度 $\rightarrow$ 重游意愿 & 0.789 & 16.936 & *** (强力支持) \\
\hline H10 & 游客行为一旅游环境 & 0.108 & 2.797 & **(支持) \\
\hline H11 & 游客行为 $\rightarrow$ 好客度 & 0.015 & 0.536 & 0.592 (不支持) \\
\hline H12 & 游客行为 $\rightarrow$ 友好意愿 & 0.021 & 0.628 & 0.530 (不支持) \\
\hline $\mathrm{H} 1 \mathrm{~b}$ & 旅游环境 $\longrightarrow$ 好客度 & 0.655 & 16.552 & *** (强力支持) \\
\hline H13 & 旅游环境一友好意愿 & 0.122 & 2.693 & **(支持) \\
\hline H14 & 好客度一友好意愿 & 0.492 & 11.301 & *** (强力支持) \\
\hline
\end{tabular}


游客的行为而改变自己的好客度和友好意愿。

旅游环境 $\rightarrow$ 友好意愿、好客度 $\rightarrow$ 友好意愿的标 客度与游客满意度呈正相关关系, 两者均对游客的 旅游体验有重要影响。此外,旅游环境质量对游客 满意度的影响力强于居民好客度的影响力, 这与游 客的直接接触强度有关。游客旅游的过程是对整 个城市旅游环境感知与评价的过程, 跟居民交往机 会却不如与环境的接触机会多,尤其是旅行团的游 客很多时候仅停留在与居民经济交易上,而散客很 多时候也仅停留在问路和简单的旅游信息咨询上。

游客满意度 $\rightarrow$ 推荐度、游客满意度 $\longrightarrow$ 重游意愿 的标准化路径系数分别为 $0.806 、 0.789, C R$ 值和 $P$ 值均显著, H8 、 H9 成立, 与已有的研究相符 ${ }^{[53]}$, 也进 一步证实了游客满意度越高, 越会推荐该旅游地, 重游该地的意愿也越强。

旅游环境一推荐度、旅游环境一重游意愿的标 准化路径系数分别为 $-0.001 、 0.027, C R$ 值分别为 $-0.035 、 0.612, P$ 值分别为 $0.972 、 0.540, \mathrm{H} 3 、 \mathrm{H} 4$ 不成 立, 即旅游环境质量与游客推荐度和重游意愿之间 的关系未得到验证。好客度 $\rightarrow$ 推荐度、好客度 $\rightarrow$ 重 游意愿的标准化路径系数分别为 $0.032 、-0.065, C R$ 值分别为 $1.036 、-1.916, P$ 值分别为 $0.300 、 0.055$, H6、H7 不成立, 即居民好客度与游客推荐度和重游 意愿之间的关系未得到验证。旅游环境和好客度 仅是与旅游地相关的两个方面, 除此之外还有旅游 安全、旅游形象等,游客满意度受这些方面的共同 决定, 推荐度和重游意愿更是如此。尤其是游客重 游意愿还与游客距目的地的距离和到该旅游地的 旅游经历有关。

游客行为 $\rightarrow$ 旅游环境的标准化路径系数为 $0.108, C R$ 值和 $P$ 值均较显著, $\mathrm{H} 10$ 成立, 游客行为越 正面, 旅游环境质量越好, 因系数较低,所以游客行 为对旅游环境质量的影响强度较弱。根据李克特 量表中对游客行为的测量, 当前游客的行为偏正 面, 对旅游环境的影响不明显。游客行为 $\rightarrow$ 好客 度、游客行为 $\rightarrow$ 友好意愿的标准化路径系数分别为 $0.015 、 0.021, C R$ 值分别为 $0.536 、 0.628, P$ 值分别为 $0.592 、 0.530$, 显然 $\mathrm{H} 11 、 \mathrm{H} 12$ 不成立, 游客行为与居 民的好客度和友好意愿的关系未得到验证。由 $\mathrm{H} 10$ 可知, 当前游客行为对旅游环境的影响较小, 并不 是影响居民生活的重要要素, 从而居民可能不会因

准化路径系数分别为 $0.122 、 0.492, C R$ 值和 $P$ 值均 较显著, H13、H14 均成立, 旅游环境质量与好客度 均正向影响居民的友好意愿。城市发展旅游业的 过程中,利益相关群体 (政府、企业) 对旅游环境的 改善使居民的生活环境越来越好。居民的利益得 到了保障,对未来游客的友好意愿便倾于正向。

\section{5 结论与讨论}

\section{1 结论}

通过上述研究, 得出以下结论:

(1)旅游环境正向影响居民好客度。从游客的 角度, 居民的热情好客是游客感知到的城市旅游环 境的一部分, 旅游环境的整体质量会正向影响游客 对居民好客度的认知; 从居民的角度, 旅游环境与 居民的生活环境关系紧密,生活环境因旅游的发展 越来越好, 居民对游客的友好度就越来越高。

(2) 旅游环境质量与居民好客度对游客满意度 有重要影响。旅游环境是游客出游的重要吸引力 之一, 随着主客交往的日渐频繁, 东道主的好客度 也逐渐发展成为影响游客满意度的重要方面, 东道 主的态度对游客的感知和评价具有重要意义。

(3) 当前游客的行为影响城市旅游环境,但不 影响居民好客度。游客行为动态地影响着旅游地 环境和居民的生活, 但总的来说在西安不是很显 著, 这跟西安当前所处的旅游地生命周期和主客交 往阶段有关。

(4)旅游环境、东道主的态度和游客的意向与 行为之间构成了相互影响的逻辑路径。东道主作 为旅游地特殊的旅游资源和信息携带者, 是游客评 价旅游环境的重要指标, 他们的态度和行为对游客 的旅游体验影响深远。而反过来游客的行为也不 断影响着东道主所生活的环境,进而影响东道主对 游客的态度。

\section{2 讨论}

(1) 东道主和游客是旅游环境中的两个关键群 体,他们之间的互动会对旅游环境产生重要影响。 东道主对其生活环境的不断塑造促使了旅游者的 出行与体验, 而旅游者行为在一定程度上影响了城 市旅游环境的发展。不可否认的是主客两者皆基 
于旅游环境探索人类与自然,进而认识世界和 自我。

(2)旅游业已成为西安市的支柱型产业, 旅游 环境问题已成为制约西安旅游可持续发展的重要 因素。基于上述的研究结论,西安市需要从三个方 面进一步提升旅游环境质量。首先要加强基础设 施的建设和自然生态环境的治理,提升西安市旅游 硬环境质量; 其次要增强东道主尤其是旅游从业人 员的服务素质和好客意识,提升西安市旅游软环境 质量; 最后要对旅西游客的行为加以适当的管理和 控制,使西安市的旅游环境朝积极的方向发展。

(3)研究的主要不足在于调研时间处于西安的 夏季, 游客对冬天西安旅游环境的感知与评价有待 进一步考察, 研究的结论有待进一步验证。此外, 理论模型中的关系都是单向的,事实上可能存在双 向联系。由于不同的城市处于旅游生命周期的不 同阶段,游客的介人程度也会影响居民的“愤怒指 数”,因此可继续对处于旅游生命周期其他阶段的 城市的旅游环境进行考察, 以进一步探讨游客行为 与居民好客度之间的关系。

\section{参考文献 (References)：}

[1] Butler R W. Tourism, environment, and sustainable development [J]. Environmental Conservation, 1991, 18(3): 201-209.

[2] 汪侠, 郎贤萍. 旅游主客交往研究进展及展望 $[\mathrm{J}]$. 北京第二外 国语学院学报, 2012, (11) : 19-29. [Wang X, Lang X P. Research on host- guest interaction in tourism: progress and prospects[J]. Journal Beijing International Studies University, 2012, (11): 19-29.]

[3] Aramberri J. The host should get lost: paradigms in the tourism theory[J]. Annals of Tourism Research, 2001, 28(3): 738-761.

[4] 卢璐. 古村落旅游区主客交往与互容性研究-以皖南宏村为例 [D]. 西安: 陕西师范大学, 2011. [Lu L. Research on HostTourist Interaction and Compatibility in the Travel Community of Ancient Village: A Case Study on South of Anhui[D]. Xi' an: Shaanxi Normal University, 2011.]

[5] 李海娥. 基于游客视角的旅游地主客交往行为研究 $[J]$. 学习与 实践, 2015, (4): 67-73. [Li H E. Research on host-tourist interaction behavior of tourism destination from the perspective of tourist[J]. Study and Practice, 2015, (4): 67-73.]

[6]欧阳军. 旅游主客交往模式、影响因子及效应评判研究-以云南
大理、丽江为例 $[D]$. 广州: 华南师范大学, 2003. [Ou Y J. A Study of Models, Effecting Factors and Effect Appraisal of Hosts- Tourists Interaction: Taking Dali and Lijiang as a Case Study[D]. Guangzhou: South China Normal University, 2003.]

[ 7 ] Pizam A, Uriely N, Reichel A. The intensity of tourist-host social relationship and its effects on satisfaction and change of attitudes: the case of working tourists in Israel[J]. Tourism Management, 2000, 21 (4): 395-406.

[ 8 ] Walls A, Shani A, Rompf P D. The nature of gratuitous referrals in tourism: local residents' perspective[J]. International Journal of Contemporary Hospitality Management, 2008, 20 (6) : 647663.

[9] 郑娜莎. 基于灰色评价的旅游环境承载力研究-以青岛城市旅 游环境系统为例 [D]. 青岛: 中国海洋大学, 2010. [Zheng N S Research on Tourism Carrying Based on Gray Evaluation- A Case of Urban Tourism Environment System of Qingdao[D]. Qingdao: Ocean University of China, 2010.]

[10] 刘振礼. 旅游环境的概念及其他-试论旅游与环境的辩证关系 [J]. 旅游学刊, 1989, 4(4): 37-40. [Liu Z L. Concept of tourism environment and others-talking about the dialectical relationship between tourism and environment[J]. Tourism Tribune, 1989, 4 (4): 37-40.]

[11] 崔凤军. 旅游环境研究的几个前沿问题[J]. 旅游学刊, 1998, 13 (5) : 35-39. [Cui F J. Several frontier problems of tourism environment [J]. Tourism Tribune, 1998, 13(5):35-39.]

[12] 徐军. 探析旅游环境保护内涵[J]. 旅游学刊, 1998, (5): 40-43. [Xu J. Analysis on connotation of tourism environment protection[J]. Tourism Tribune, 1998, (5): 40-43.]

[13] 陈安泽, 卢云亭. 旅游地学概论 [M]. 北京: 北京大学出版社, 1991. [Chen A Z, Lu Y T. Introduction to Tourism Destination Study[M]. Beijing: Peking University Press, 1991.$]$

[14] 林炎钊. 桂林旅游业发展的大视野-文化的切入 $[\mathrm{J}]$. 旅游研究 与实践, 1995, (1): 48-52. [Lin Y Z. Vision of tourism industry development-cut-over the culture[J]. Research and Practice of Tourism, 1995, (1): 48-52.]

[15] 林越英. 对旅游环境基本理论问题的初步探讨 [J]. 北京第二外 国语学院学报, 1998, (1) : 32-35. [Lin Y Y. Preliminary discussion on the basic theory to tourism environment [J]. Journal Beijing International Studies University, 1998, (1):32-35.]

[16] 吴成基,彭永祥, 孟彩平, 等. 旅游区三重旅游环境系统及其优 化调控-以西安为例 [J]. 旅游学刊, 2001, 16(4): 52-54. [Wu C J, Peng Y X, Meng C P, et al. Tri-Tourism environment system (TTES) and the optimization control in domestic tourism areastake Xi' an as an example[J]. Tourism Tribune, 2001, 16(4): 5254.]

[17] 伍向阳. 城市旅游环境竞争力评价研究-以广州市为例 [D]. 北 京: 中国科学院, 2007. [Wu X Y. The Study of Evaluation on 
Urban Tourism Environment Competitiveness- A Case Study of Guangzhou, China[D]. Beijing: Chinese Academy of Sciences, 2007.]

[18] 刘佳, 于水仙, 王佳. 滨海旅游环境承载力评价与量化测度研 究-以山东半岛蓝色经济区为例 $[\mathrm{J}]$. 中国人口・资源与环境, 2012, 22(9) : 163-170. [Liu J, Yu S X, Wang J. Evaluation and quantitative measurement on coastal tourism environmental carrying capacity: a case study on the blue Shandong peninsula economic zone[J]. China Population Resources and Environment, 2012,22(9): 163-170.]

[19] 万绪才, 张安, 李刚, 等. 基于旅游者的城市旅游环境质量综合 评价研究-南京与苏州两市实例分析 [J]. 经济地理, 2003, 23 (1) : 113-116. [Wang X C, Zhang A, Li G, et al. Study on synthetical evaluation for tourism environment quality of city in view of tourists-a case study of Nanjing and Suzhou[J]. Economic Geography, 2003,23(1): 113-116.]

[20] 胡巧娟. 基于微观视角的乡村旅游地居民旅游效应感知与态 度研究 [D]. 西安: 陕西师范大学, 2013. [Hu Q J. Research on the Perception of Tourism Impacts and Attitudes of Residents at Rural Tourism Destination[D]. Xi' an: Shaanxi Normal University, 2013.]

[21] 李如友, 黄常州. 旅游地居民的旅游影响感知对态度的影响作 用-以常州环球恐龙城为例 [J]. 旅游论坛, 2013, 6(4): 45-52. [Li R Y, Huang C Z. Effects of residents' perception of tourism impacts on their attitude-a case study of global dinosaurs town in Guangzhou city[J]. Tourism Forum, 2013, 6(4): 45-52.]

[22] 高智艳. 国外旅游环境研究进展与现状 $[\mathrm{J}]$. 新西部: 下旬・理 论, 2014, (8): 167-168. [Gao Z Y. Foreign research progress and status of tourism environment[J]. New Western, 2014, (8) : 167 168.]

[23] Saveriades A. Establishing the social tourism carrying capacity for the tourist resorts of the east coast of the Republic of Cyprus [J]. Tourism Management, 2000, 21(2): 147-156.

[24] Muzaler U, Joseph S C, Daniel R W. Increasing state market share through regional positioning[J]. Tourism Management, 2000, 21(1): 89-96

[25] Ogutu Z A. The impact of ecotourism on livelihood and natural resource management in Eselenkei, Amboseli ecosystem, Kenya [J]. Land Degradation \& Development, 2002, 13(3): 251-256.

[26] Murphy P E. Community driven tourism planning[J]. Tourism Management, 1988, 9(2): 96-104.

[27] Dieke P U C. Tourism in the Gambia: some issues in development policy[J]. World Development, 1993, 21(2): 277-289.

[28] Kozak M, Martin D. Tourism life cycle and sustainability analysis: profit- focused strategies for mature destinations[J]. Tourism Management, 2012, 33(1): 188-194.

[29] Lordkipanidze M, Brezet H, Backman M. The entrepreneurship factor in sustainable tourism development[J]. Journal of Cleaner Production, 2005, 13(8): 787-798.

[30] Ayers J S, Potter H R. Attitudes toward community change: A comparison between rural leaders and residents[J]. Journal of the Community Development Society, 1989, 20(1): 1-18.

[31] Volo S. A consumer based measurement of tourism innovation [J]. Quality Assurance in Hospitality \&Tourism, 2006, 6 (3-4): 73-87.

[32] 杜忠潮, 文琦, 蔡平, 等. 关中地区都市旅游环境质量综合评价 研究-西安, 咸阳和宝鸡实证对比分析 $[\mathrm{J}]$. 干旱区资源与环境, 2007, 21 (9) : 106-111. [Du Z C, Wen Q, Cai P, et al. A research on synthesis appraisal of metropolis tourist environment quality in Guanzhong area-a demonstrating contrast and analysis on Xi' an, Xianyang and Baoji[J]. Journal of Arid Resources and Environment, 2007,21(9): 106-111.]

[33] 郭雅宁. 旅游目的地旅游环境建设规划研究-以西安市为例 [D]. 西安: 西安建筑科技大学, 2009. [Guo Y N. Study on Planning of Tourist Environmental Construction in Tourist Destination- Illustrated by Xi'an[D]. Xi'an: Xi'an University of Architecture and Technology, 2009.]

[34] 张悦. 基于市场调查的旅西外国游客西安旅游诸项评价研究 [D]. 西安：陕西师范大学, 2014. [Zhang Y. Xi'an Tourism Evaluation of Inbound Tourist Based on Market Research[D]. Xi'an: Shaanxi Normal University, 2014.]

[35] 马明, 彭淑贞. 基于游客感知的山东居民好客度研究 $[\mathrm{J}]$. 合作 经济与科技, 2016，(10)：138-140. [Ma M, Peng S Z. Host's hospitality degree in Shandong based on tourist perception[J]. CO-Oerativeconomy \& Science, 2016, (10): 138-140.]

[36] 李天元, 向招明. 目的地旅游产品中的好客精神及其培育 [J]. 华侨大学学报: 哲学社会科学版, 2006, (4) : 66-72. [Li T Y, Xiang Z M. On hospitality spirit in tourism and its development [J]. Journal of Huaqiao University (Philosophy \& Social Sciences), 2006, (4): 66-72.]

[37] 李正欢. 旅游业“好客”研究的多维视野审视 [J]. 北京第二外国 语学院学报, 2009, 31 (11): 25-31. [Li Z H. The study on hospitality in tourism industry: multidimensional perspectives [J]. Journal Beijing International Studies University, 2009, 31 (11): 25-31.]

[38] 李春霞. 好客的东道主: 旅游人类学“主-客”范式反思 $[\mathrm{J}]$. 广西 民族大学学报 (哲学社会科学版), 2012, 34 (5): 23-28. [Li C $\mathrm{X}$. Hospitable host: Reflections on the host- guest paradigm in anthropology of tourism[J]. Journal of Guangxi University for Nationalities (Philosophy and Science Edition), 2012, 34 (5): 23-28.]

[39] 林敏霞. 好客“边界”与现代旅游 [J]. 广西民族大学学报(哲学 社会科学版)，2012，34 (5) : 29-33. [Lin M X. Hospitality "boundary" and modern tourism[J]. Journal of Guangxi Univer- 
sity for Nationalities (Philosophy and Science Edition), 2012, 34 (5): 29-33.]

[40] 刘军林. 好客旅游开发中的本真性问题研究 [J]. 湖北社会科 学, 2011, (4): 111-113. [Liu J L. Authenticity of hospitality tourism development[J].Hubei Social Sciences, 2011, (4): 111-113.]

[41] 王宁. 旅游中的互动本真性: 好客旅游研究 [J]. 广西民族大学 学报 (哲学社会科学版), 2007,29(6): 18-24. [Wang N. Interactive authenticity in tourism-a case study on hospitality tourism [J]. Journal of Guangxi University for Nationalities (Philosophy and Science Edition), 2007, 29(6): 18-24.]

[42] 陈方英, 郑冬海, 耿禧则, 等. 日本游客对好客山东旅游形象认 知与评价研究 [J]. 旅游发展研究, 2011, (2): 16-20. [Chen F Y, Zheng D M, Geng X Z, et al. A study on the evaluation of the tourism destination image slogan of friendly Shandong based on the Japanese perspective[J]. Journal of tourism development, 2011, (2): 16-20.]

[43] 吕翠芹. “好客山东”旅游目的地品牌评价指标体系的构建 [D]. 济南: 山东财经大学, 2012. [Lv C Q. Construction of the "Friendly Shandong" Tourism Destination Brand Evaluation Index System[D]. Ji' nan: Shandong University of Finance and Economics, 2012.]

[44] 宋佳. “好客山东”旅游目的地营销模式研究[D]. 济南: 山东大 学, 2010. [Song J. “Friendly Shandong” Tourism Destination Marketing Model[D]. Ji'nan: Shandong University, 2010.]

[45] 李西香. 旅游目的地品牌建设研究-以“好客山东”旅游品牌为 例 [J]. 经济研究导刊, 2009, (17): 173-174. [Li X X. Research on tourism destination brand construction- a case study on “friendly Shandong”[J]. Economic Research Guide, 2009, (17): 173-174.]

[46] 张广海, 刘佳. 山东省旅游品牌的开发与对策[J]. 中国海洋大 学学报 (社会科学版), 2009, (4) : 64-68. [Zhang G H, Liu J The development and countermeasure of tourism brand of Shandong[J].Journal of Ocean University of China (Social Sciences), $2009,(4): 64-68$.

[47] 马红丽. 中国旅游热点城市入境游客居民好客度感知研究 [D]. 西安: 陕西师范大学, 2010. [Ma H L. Host Hospitality Perception of Inbound Tourists at Hot Spot Tourist City[D]. Xi' an: Shaanxi Normal University, 2010.]

[48] Doxey G V. A Causation Theory of Visitor-Resident Irritants[C].
San Diego: proceedings of the Sixth Annual Conference on Travel and Tourism Research Association, 1975.

[49] Butler R W. The concept of a tourist area cycle of evolution: implications for management of resources[J]. Canadian Geographer, 1980, 24(1):5-12.

[50] 连渏, 汪侠. 旅游地顾客满意度测评指标体系的研究及应用 [J]. 旅游学刊, 2004, 19(5): 9-13. [Lian Y, Wang X. A case study and application of customer satisfaction evaluation system in tourist destination based on TDCSI[J]. Tourism Tribune, 2004, 19(5): 9-13.]

[51] 王群, 丁祖荣, 章锦河, 等. 旅游环境游客满意度的指数测评模 型 - 以黄山风景区为例 [J]. 地理研究, 2006, 25 (1): 171-181. [Wang Q, Ding Z R, Zhang J H, et al. Study on the model of tourist satisfaction index about tourism environment: a case study of Huangshan Mountain[J]. Geographical Research, 2006, 25(1): 171-181.]

[52] 范英. 峨眉山景区旅游环境游客满意度测评研究[D]. 成都: 西 南交通大学, 2006. [Fan Y. The Evaluation and Research of Tourist's Satisfaction Definition about Emei Tour Environment [D]. Chengdu: Southwest Jiaotong University, 2006.]

[53] 赵玉婷, 苏建军. 五老峰国家森林公园体育旅游环境游客满意 度测评 [J]. 体育研究与教育, 2016, 31(2): 36-40. [Zhao Y T, Su J J. Tourist satisfaction evaluation on sport tourism environment of Wulaofeng national forest park[J]. Sports Research and Education, 2016, 31(2): 36-40.]

[54] 孟威. 旅游主客交往理论基础与实证初步研究-以周庄为例 [D]. 芜湖: 安徽师范大学, 2007. [Meng W. A Preliminary Research on the Theoretical Basis and Empirical Analysis of "Host- guest Interaction" - A Case Study of Zhouzhuang[D]. Wuhu: Anhui Normal University, 2007.]

[55] 孟威, 苏勤. 历史城镇类旅游地居民交往偏好分化及测度 $[\mathrm{J}]$ 旅游学刊, 2009, 24(5): 54-60. [Meng W, Su Q. On the stratification and measurement of residents' preferences of tourist destinations in the category of historic towns- a case of Zhouzhuang[J]. Tourism Tribune, 2009, 24(5): 54-60.]

[56] 吴明隆. 结构方程模型: AMOS 的操作与应用 [M]. 重庆: 重庆 大学出版社, 2010. [Wu M L. SEM: The Operation and Application of AMOS[M]. Chongqing: Chongqing University Press, 2010.] 


\title{
Tourism environment perception and evaluation based on host-tourist interactions in Xi' an City
}

\author{
CHEN Zhigang, LIU Dan, LIU Junsheng \\ (School of Geography and Tourism, Shaanxi Normal University, Xi' an 710119, China)
}

\begin{abstract}
The host and tourist are two key groups whose interaction has a great effect on the tourism environment. Taking $\mathrm{Xi}^{\prime}$ an as an example and using questionnaire and structural equal modeling, we researched host and tourist perceptions and explored interactions amongst the tourism environment, host and tourist. The results show that tourism environment quality has a positive impact on hospitality degree, hospitality intention and tourist satisfaction. There is a positive correlation between hospitality and tourist satisfaction, and tourist behavior has a positive impact on tourism environment, but no significant impact on hospitality. There is a logical path formed by the tourism environment, host attitude and tourist intentions and behavior, and the three affect each other. As a special tourism resource and carrier of tourism, the host is an important indicator for tourists to evaluate the tourism environment. Their attitudes and behaviors have a profound influence on the tourist experience. In turn, the behavior of tourists constantly influences the living environment of hosts, thus affecting host attitudes towards tourists. From the perspective of host-tourist interaction, we provide suggestions for the promotion of urban tourism environment quality perception and evaluation. First, the construction of infrastructure and the management of the natural ecological environment should be strengthened to improve the quality of the hard tourism environment in $\mathrm{Xi}^{\prime}$ an. Second, it is important to enhance service quality and the hospitality consciousness of hosts, especially tourism staff, to improve the quality of the soft tourism environment in Xi' an. The tourism environment of Xi' an should be properly managed and controlled in order to develop in a positive direction.
\end{abstract}

Key words: tourism environment; hospitality; tourist satisfaction; tourist behavior; host- tourist interaction; Xi' an City 